\title{
Cardiovascular Response to Core Stability Exercises on Swiss Ball and Floor in Hypertensive Individuals
}

\author{
Bharvi Malavia ${ }^{1}$, Sweety Shah ${ }^{2}$ \\ ${ }^{1}$ MPT, Assistant Professor, Khyati College of Physiotherapy, Palodia, Ahmedabad, Gujarat, India \\ ${ }^{2}$ Ph.D., MPT, Lecturer, SBB College of Physiotherapy, VS General Hospital, Ahmedabad, Gujarat, India \\ Corresponding Author: Bharvi Malavia
}

DOI: https://doi.org/10.52403/ijhsr.20220234

\begin{abstract}
Background: Hypertension is one of the most important modifiable risk factors for cardiovascular disease. Core stability exercises are common exercises prescribed to individuals who wish to strengthen abdominals. Swiss ball exercises will produce isotonic as well as isometric contraction in muscles. Isometric contraction of muscles will produce lot of physiological changes. Dynamic exercises also produce modest effect on arterial blood pressures. This study aims to compare and determine the effectiveness of two core stability exercises on Swiss ball and floor exercises on cardiovascular parameters in hypertensive individuals.

Method: A total of 30 hypertensive individuals participated in the study. They were divided in 2 groups: Group-A and Group-B. Baseline measurement of cardiovascular parameters i.e. systolic and diastolic blood pressure (BP) was recorded using sphygmomanometer and heart rate (HR) using pulse oximeter. Both group A and B performed 4 types of core stability exercises i.e. curl-ups, bridging, side planks and front planks on Swiss ball and Floor mat respectively. Each exercise was done for 10 repetitions with 10 seconds hold of 3 sets for 3 days a week for 6 weeks. Blood pressure and heart rate was measured again at end of 6 weeks.

Result: Paired t-test suggested significant improvement on cardiovascular responses in both groups. Unpaired t-test showed significant improvement in cardiovascular parameters of group A when compared to group B after core stability exercises $(\mathrm{p}<0.05)$.

Conclusion: The study concludes that core stability exercises have significant improvement on cardiovascular responses in both groups. However, group A showed better improvement compared to group B.
\end{abstract}

Key Words: Hypertension, Core stability, Cardiovascular responses, Swiss ball exercises.

\section{INTRODUCTION}

Elevated blood pressure, also known as hypertension, is one of the most important modifiable risk factors for cardiovascular disease and is accounting for $10 \%$ of overall deaths in India ${ }^{[1]}$. In a metaanalysis of 142 studies from rural and urban populations of India, it was concluded that hypertension is emerging as a major health problem in India ${ }^{[2]}$ and is more in urban than in rural subjects ${ }^{[3]}$.

Hypertension alone is a risk factor for several cardiovascular diseases ${ }^{[4]}$, such as stroke, coronary heart disease, heart failure, peripheral arterial disease, and renal insufficiency ${ }^{[5]}$. Independently, the decrease in blood pressure (BP), heart rate (HR), and rate-pressure product (RPP) reduces the risk of vascular disease ${ }^{[5]}$.

Regular physical exercise has been recommended for the prevention and treatment of hypertension ${ }^{[6,7,8]}$. It has been shown that active subjects have a lower risk of becoming hypertensive than do sedentary subjects $^{[8,9]}$. Moreover, many researchers have shown that a single episode of exercise 
is able to reduce blood pressure during the recovery period. ${ }^{[8]}$ In addition, metaanalyses have concluded that aerobic training is effective in reducing clinical blood pressure in the general population as well as in hypertensive patients ${ }^{[8,9]}$.

This type of exercise activity can have numerous benefits. These include stabilization of the core of the body, ${ }^{[10]}$ reduction in lower back pain, ${ }^{[11,12]}$ reduction in plasma lipids, ${ }^{[13]}$ increased recovery and oxygen kinetics following exercise training, ${ }^{[14]}$ improvement in function in cardiac patients, ${ }^{[15]}$ better blood pressure control in stabilizing orthostatic intolerance, ${ }^{[16]}$ and increased skeletal muscle blood flow, which has been linked to nitric oxide production $^{[1]}$.

The abdominal or core muscles, however, are unique. Strengthening these muscles not only has strong central effects in the body, such as cardiovascular training, but also causes an increase in stability of the trunk to extend during reach and functional activities $^{[18]}$.

Traditionally, abdominal crunches have been used to train the core muscles of the body ${ }^{[19,20]}$. But, abdominal crunches provide only low levels of muscle activity since the only resistance to core muscle activity is the body weight ${ }^{[18,21,22]}$. Therefore, large numbers of repetitions are needed to train. To increase muscle work, devices such as Swiss balls have been used as an adjunct to abdominal crunches. By performing exercise on a Swiss ball, there is decreased balance stability during exercise, thereby increasing muscle work in the core muscles $^{[23,24,25]}$. The Swiss ball offers the advantage over floor crunches in that exercise on the Swiss ball allows a greater extension during abdominal exercise compared with lying on the floor ${ }^{[23,24,25]}$. This study aims to compare and determine the effectiveness of two core stability exercises on Swiss ball and floor exercises on cardiovascular parameters in hypertensive individuals.

\section{MATERIALS AND METHODOLOGY}

An experimental study with 30 subjects was selected using simple random sampling method. This study included hypertensive individuals between the age group from 30 to 50 years, those who were able to do Swiss ball exercises, not involved in any other form of exercises, both male and female were included. Individuals with any neurological or musculoskeletal complain, or any sort of cardiac diseases or not willing to participate were excluded from the study. A clear explanation and the purpose of the study was given to all the participants.

The participants were divided into two groups: Group A and Group B.

Group A- core stability exercises on Swiss ball

Group B- core stability exercises on floor.

All the participants were involved in four set of core stability exercises.

Exercises included:

a) Curl-up

b) Bridging

c) Front plank

d) Side plank

\section{Exercise for Swiss ball group \\ Curl-up on Swiss ball}

- Starting position: Start in supine position with lower back supported on the ball. Hands are clasped behind the head. Feet are shoulder width apart. Draw lower abdominal muscles towards the spine.

- Procedure: Slowly flex the spine while keeping abdominal muscles drawn in. Return to starting the position.

- Instruction: Keep cervical neutral by keeping the chin tucked.

\section{Bridging on Swiss ball}

- Starting position: Start in supine position with arms out to the side. Place feet on the ball, toes pointed forward. Draw abdominal muscles in towards the spine. 
- Procedure: Contract the abdominals and gluteus and lift hips off the floor.

- Instruction: Avoid rotating toes outwards.

\section{Front plank on Swiss ball}

- Starting position: Subject assumes a front plank position on the Swiss ball with elbow under the shoulder and upper arm perpendicular to the ground.

- Procedure: Slowly lift the shoulder and pelvis off the ground, supporting points will be on elbow and feet.

- Instructions: Balance the forearm under the shoulder and keep your spine neutral and drawing in your lower stomach.

\section{Side plank on Swiss ball}

- Starting position: Lying on your side, keeping lateral surface of down leg on ball.

- Procedure: Prop yourself on your right elbow placed directly under your shoulder. Lift yourself off the ground supporting your body on your right elbow and ball.

- Instructions: Maintain neutral alignment of the hips, not allowing the top hip to roll front or back. Avoid laterally flexing the cervical spine or letting the head tip to the side. Let the supporting arm assist with balance, but avoid pushing the body up with the arm.

\section{Exercise for Floor Group \\ Curl-up on floor}

- Starting position: Supine crook lying position with arms aver the head.

- Procedure: Slowly curl your trunk, letting your shoulders and upper back lift off the ground. Return slowly to starting position.

- Instruction: Avoid pulling on the head or neck. Return to neural posture between each repetition.

\section{Bridging on floor}

- Starting position: Supine crook lying, with hands at the side of the body, palm facing downwards.
- Procedure: Slowly raise the hips off the grounds so that only forearms and heels are touching the ground.

- Instruction: Weight is supported across the shoulder area. Avoid pressing the cervical spine into the floor. Maintain neutral posture in the lumbar and cervical spine throughout.

\section{Front plank on floor}

- Starting position: Subject assumes a front plank position with elbow under the shoulder and upper arm perpendicular to the ground.

- Procedure: Slowly lift the shoulder and pelvis off the ground, supporting points will be on elbow and feet.

- Instructions: Balance the forearm under the shoulder and keeping your spine neutral and drawing in your lower stomach

\section{Side plank on floor}

- Starting position: Subject assume a side plank position with elbow under the shoulder and upper arm perpendicular to the ground.

- Procedure: Slowly lift the shoulder and pelvis off the ground, supporting points will be on elbow and feet.

- Instruction: Balance the forearm under the shoulder and the same side foot while attempting to keep the body aligned in a straight line.

All participants performed each exercise was for 10 repetitions with 10 seconds hold of 3 sets for 3 days a week for 6 weeks. Cardiovascular parameters i.e. systolic blood pressure (SBP) and diastolic blood pressure (DBP) was recorded using sphygmomanometer and heart rate (HR) using pulse oximeter. The data were collected on the first visit of the patient and at the end of third week.

\section{STATISTICAL ANALYSIS}

Statistical analysis has been carried out to analyze the significant impact of the treatment issued to the individuals in both 
Bharvi Malavia et.al. Cardiovascular response to core stability exercises on Swiss ball and floor in hypertensive individuals.

the groups. For this purpose the data was entered into Microsoft excel spread sheet, tabulated and subjected to statistical analysis using SPSS version 16 . Normality was assessed by the Shapiro Wilk test. All data are presented as mean \pm standard deviation (SD).

Statistical tools such as unpaired ttest has been applied for parameters in between groups and paired sample t-test for parameters within group. Level of significance was fixed at 5\% $(\mathrm{p}<0.05)$.

\section{RESULTS}

A total of 30 hypertensive individuals participated in the study. Group $A$ and $B$ each had 15 individuals with mean age of $40.13 \pm 5.08$ and $39.33 \pm 5.90$ years respectively. There was no significant difference in the age between the two groups $(\mathrm{P}=0.446)$.

After a 6 week protocol period, the subjects in floor exercise group and Swiss ball group had shown improvement with the outcome measures. But on comparing both the groups, Swiss ball group had shown a statistically significant improvement at 0.05 level with the outcome measures.

Table 1: Demographic data

\begin{tabular}{|l|l|l|}
\hline & Group A & Group B \\
\hline Mean age (years) & 40.13 & 39.33 \\
\hline Gender & \multicolumn{2}{|l|}{} \\
\hline Male & 9 & 7 \\
\hline Female & 6 & 8 \\
\hline
\end{tabular}

Table 2: Mean of pre and post test cardiovascular parameters of Group A

\begin{tabular}{|l|l|l|l|l|l|l|l|}
\hline Parameters & & N & Mean & SD & t- value & p- value & Interpretation \\
\hline \multirow{2}{*}{ Heart rate (beats/min) } & Pre & 15 & 84.44 & 7.38 & 10.40 & 0.000 & \multirow{2}{*}{ Significant } \\
\cline { 2 - 7 } & Post & 15 & 69.73 & 5.85 & & & \\
\hline \multirow{2}{*}{ Diastolic Blood Pressure (mmHg) } & Pre & 15 & 144.33 & 3.72 & 12.65 & 0.000 & \multirow{2}{*}{ Significant } \\
\cline { 2 - 7 } & Post & 15 & 131.00 & 5.07 & & & \\
\cline { 2 - 6 } & Pre & 15 & 92.67 & 5.30 & 10.46 & 0.000 & \multirow{2}{*}{ Significant } \\
\cline { 2 - 6 } & Post & 15 & 84.33 & 3.71 & & & \\
\hline
\end{tabular}

Table 3: Mean of pre and post test cardiovascular parameters of Group B

\begin{tabular}{|c|c|c|c|c|c|c|c|}
\hline & & $\mathbf{N}$ & Mean & SD & t- value & p- value & Interpretation \\
\hline \multirow[t]{2}{*}{ Heart rate (beats/min) } & Pre & 15 & 81.93 & 6.47 & \multirow[t]{2}{*}{19.00} & \multirow[t]{2}{*}{0.000} & \multirow[t]{2}{*}{ Significant } \\
\hline & Post & 15 & 76.87 & 6.66 & & & \\
\hline \multirow[t]{2}{*}{ Systolic Blood Pressure (mmHg) } & Pre & 15 & 144.67 & 4.42 & \multirow[t]{2}{*}{14.00} & \multirow[t]{2}{*}{0.000} & \multirow[t]{2}{*}{ Significant } \\
\hline & Post & 15 & 140.00 & 4.63 & & & \\
\hline \multirow{2}{*}{ Diastolic Blood Pressure (mmHg) } & Pre & 15 & 93.67 & 4.42 & \multirow[t]{2}{*}{6.21} & \multirow[t]{2}{*}{0.000} & \multirow[t]{2}{*}{ Significant } \\
\hline & Post & 15 & 90.00 & 4.63 & & & \\
\hline
\end{tabular}

Table 4: Comparison of mean values of cardiovascular parameters between Group A and B

\begin{tabular}{|c|c|c|c|c|c|c|c|c|}
\hline & & Group & $\mathbf{N}$ & Mean & SD & t- value & p- value & Interpretation \\
\hline \multirow{4}{*}{$\begin{array}{l}\text { Heart rate (beats/ } \\
\text { min) }\end{array}$} & \multirow[t]{2}{*}{ Pre } & $\mathrm{A}$ & 15 & 84.44 & 7.38 & \multirow[t]{2}{*}{0.973} & \multirow[t]{2}{*}{0.339} & \multirow[t]{2}{*}{ Not significant } \\
\hline & & $\mathrm{B}$ & 15 & 81.93 & 6.47 & & & \\
\hline & \multirow[t]{2}{*}{ Post } & $\mathrm{A}$ & 15 & 69.73 & 5.85 & \multirow[t]{2}{*}{-3.116} & \multirow[t]{2}{*}{0.004} & \multirow[t]{2}{*}{ Significant } \\
\hline & & $\mathrm{B}$ & 15 & 76.87 & 6.66 & & & \\
\hline \multirow[t]{4}{*}{ Systolic Blood Pressure (mmHg) } & \multirow[t]{2}{*}{ Pre } & A & 15 & 144.33 & 3.72 & \multirow[t]{2}{*}{-0.224} & \multirow[t]{2}{*}{0.825} & \multirow[t]{2}{*}{ Not significant } \\
\hline & & $\mathrm{B}$ & 15 & 144.67 & 4.42 & & & \\
\hline & \multirow[t]{2}{*}{ Post } & $\mathrm{A}$ & 15 & 131.00 & 5.07 & \multirow[t]{2}{*}{-5.077} & \multirow[t]{2}{*}{0.000} & \multirow[t]{2}{*}{ Significant } \\
\hline & & $\mathrm{B}$ & 15 & 140.00 & 4.63 & & & \\
\hline \multirow[t]{4}{*}{ Diastolic Blood Pressure (mmHg) } & \multirow[t]{2}{*}{ Pre } & $\mathrm{A}$ & 15 & 92.67 & 5.30 & \multirow[t]{2}{*}{0.561} & \multirow[t]{2}{*}{0.579} & \multirow[t]{2}{*}{ Not significant } \\
\hline & & $\mathrm{B}$ & 15 & 93.67 & 4.42 & & & \\
\hline & \multirow[t]{2}{*}{ Post } & $\mathrm{A}$ & 15 & 84.33 & 3.71 & \multirow[t]{2}{*}{-3.697} & \multirow[t]{2}{*}{0.001} & \multirow[t]{2}{*}{ Significant } \\
\hline & & $\mathrm{B}$ & 15 & 90.00 & 4.63 & & & \\
\hline
\end{tabular}

On performing the unpaired sample t-test, it is observed that there is no statistical significant difference between the pre test parameters of heart rate $(\mathrm{p}=0.873)$, systolic blood pressure $(\mathrm{p}=0.790)$ and diastolic blood pressure $(p=0.596)$ between Group A and B.

A statistical significance was observed between the post test parameters of heart rate $(\mathrm{p}=0.043)$, systolic blood pressure $(\mathrm{p}=0.012)$ and diastolic blood pressure ( $\mathrm{p}=0.033$ ) between Group A and B. Group A had shown a statistically significant improvement compared to Group B. 


\section{DISCUSSION}

This study was conducted to compare and determine the effectiveness of core stability exercises on Swiss ball and floor exercises on cardiovascular parameters in hypertensive individuals.

The result showed that there is a statistical significance existing between all the pairs of cardiovascular parameters of pre and post test of Group A i.e. the Swiss ball group and Group B i.e. the Floor exercise group. There was no statistical significance observed between the pre test parameters of heart rate, systolic blood pressure and diastolic blood pressure between Group A and B. However, the post test parameters of heart rate, systolic blood pressure and diastolic blood pressure between Group A and B were statistically significant. Group A had shown a statistically significant improvement compared to Group B.

The decrease in the heart can be justified by the fact that exercises create an imbalance between the tonic activity of sympathetic accelerator and parasympathetic depressor neurons in favor of greater vagal dominance, a response mediated primarily by increased parasympathetic activity and a small decrease in sympathetic discharge ${ }^{[26]}$. The decrease in both systolic and diastolic blood pressure were observed, maybe because of favorable changes in vascular compliance, which might have occurred after exercise training thus could reduce peripheral resistance $^{[27]}$.

Hainsworth $\mathrm{R}$ et al reported that resting heart rate is determined by parasympathetic nervous system and diastolic blood pressure is a function of peripheral vascular resistance which is determined by sympathetic nervous system. [28] According to Ganong, the increase in parasympathetic activity decreases resting heart rate and decrease in sympathetic tone in skeletal muscle blood vessels decreases peripheral vascular resistance resulting in decrease in diastolic BP, mean arterial pressure, reduced work load on heart and improved tissue perfusion. ${ }^{[29]}$
Exercise can reduce the blood level of nor-epinephrine which can limit the vasoconstriction of the arterioles and decrease the peripheral resistance to blood pressure. Simultaneously, a slight reduction in sympathetic neural activity may help to modify this decrease in blood pressure ${ }^{[30]}$.

There was a significant difference in the cardiovascular parameter of group A compared to group B due to greater muscle work required to perform the exercises. Regular training confers beneficial effects on the heart as well the entire body. This occurs partly because exercise training improves skeletal muscle work capacity and reduces resistance, thus increases conductance in the peripheral circulation. Extrinsic modulation of the heart alters and improves the intrinsic pump capacity of the heart $^{[31]}$.

\section{CONCLUSION}

This study concludes that there was a significant reduction in the heart rate, systolic and diastolic blood pressure after 6 weeks of core stability exercises in both the groups, However, group A showed significant results compared to group B.

\section{Limitations}

- The sample size of the study was small therefore the results can not be generalised.

- The training duration could be increased.

\section{ACKNOWLEDGEMENT}

I express my profound thanks to my guide Dr. Sweety Shah, who encouraged me to pursue this topic and spend extra time helping me achieve a clear structure. I am also grateful to all the subjects who participated in the study. My appreciation also extends to the staff and faculty of S.B.B College of Physiotherapy for their genuine kindness and also helped sustain a positive atmosphere.

Conflict of Interest: None 
Bharvi Malavia et.al. Cardiovascular response to core stability exercises on Swiss ball and floor in hypertensive individuals.

\section{Source of Funding: None}

\section{Ethical Approval: Approved}

\section{REFERENCES}

1. V. Patel, S. Chatterji, D. Chisholm et al., "Chronic diseases and injuries in India," The Lancet, vol. 377, no. 9763, pp. 413428, 2011.

2. R. Anchala, N. K. Kannuri, H. Pant et al., "Hypertension in India: a systematic review and meta-analysis of prevalence, awareness, and control of hypertension," Journal of Hypertension, vol. 32, no. 6, pp. 11701177, 2014.

3. R. Gupta, "Convergence in urban-rural prevalence of hypertension in India," Journal of Human Hypertension, vol. 30,no. 2, pp. 79-82, 2016.

4. R. S. Paffenbarger Jr., "Contributions of epidemiology to exercise science and cardiovascular health," Medicine and Science in Sports and Exercise, vol. 20, no. 5, pp. 426-438, 1988.

5. L. S. Pescatello, B. A. Franklin, R. Fagard, W. B. Farquhar, G. A. Kelley, and C. A. Ray, "American college of sports medicine position stand. Exercise and hypertension," Medicine and Science in Sports and Exercise, vol. 36, no. 3, pp. 533-553, 2004.

6. V Brazilian guidelines on arterial hypertension. São Paulo: Brazilian Society of Cardiology, Brazilian Society of Hypertension, Brazilian Society of Nephrology; 2006. https://doi.org/10.1590/S0066782X2007001500012

7. Chobanian AV, Bakris GL, Black HR, Cushman WC, Green LA, Izzo JL, et al. The Seventh Report of the Joint National Committee on Prevention, Detection, Evaluation, and Treatment of High Blood Pressure: the JNC 7 report. Jama. 2003;289:2560-72.

8. Pescatello LS, Franklin BA, Fagard R, Farquhar WB, Kelley GA, Ray CA. American College of Sports Medicine position stand. Exercise and hypertension. Med Sci Sports Exerc. 2004;36:533-53.

9. Fagard RH. Exercise is good for your blood pressure: effects of endurance training and resistance training. Clin Exp Pharmacol Physiol. 2006;33:853-6.
10. Sternlicht E, Rugg S, Fujii LL,Tomomitsu KF, Seki MM. Electromyographic comparison of a stability ball crunch with a traditional crunch. J Strength Cond Res. 2007; 21:506-509.

11. Deyo RA. Conservative therapy for low back pain. Distinguishing useful from useless therapy. JAMA. 1983;250:10571062.

12. Donchin M,Woolf O, Kaplan L, Flooman Y. Secondary prevention of low-back pain.A clinical trial. Spine. 1990;15:1317-1320.

13. Herd SL, Kiens B, Boobis LH, Hardman AE. Moderate exercise, postprandial lipemia, and skeletal muscle lipoprotein lipase activity. Metabolism. 2001;50:756762.

14. Burnley M, Doust JH, Carter H, Jones AM. Effects of prior exercise and recovery duration on oxygen uptake kinetics during heavy exercise in humans. Exp Physiol. 2001;86:417- 425.

15. McConnel TR, Laubach CA III. Elderly cardiac rehabilitation patients show greater improvements in ventilation at submaximal levels of exercise. Am J Geriatr Cardiol. 1996;5:15-23.

16. Gallagher KM, Fadel PJ, Stromstad M, et al. Effects of exercise pressor reflex activation on carotid baroreflex function during exercise in humans. J Physiol. 2001;15;533(Pt 3):871- 880.

17. Agostoni P, Bussotti M. Exhaled nitric oxide and exercise performance in heart failure. Arch Physiol Biochem. 2003; 111:293-296.

18. Petrofsky JS, Cuneo M, Dial R, et al. Core strengthening in a geriatric population. $\mathrm{J}$ Appl Res Clin Exp Ther. 2005;5:423-433.

19. Sands WA, McNeal JR. A kinematic comparison of four abdominal training devices and a traditional abdominal crunch. J Strength Cond Res. 2002;16:135-141.

20. Thomas TR, Ridder MB. Resistance exercise program effects on abdominal function and physique. J Sports Med Phys Fitness. 1989;29:45-48.

21. Petrofsky JS, Morris A, Bonacci J, et al. Aerobic training on a portable abdominal machine. J Appl Res Clin Exp Ther. 2003; 3:402-415.

22. Petrofsky JS, Morris A, Bonacci J, et al. Comparison between an abdominal curl with times curls on a portable abdominal 
Bharvi Malavia et.al. Cardiovascular response to core stability exercises on Swiss ball and floor in hypertensive individuals.

machine. J Appl Res Clin Exp Ther. 2003; 3:394-401.

23. Behm DG, Anderson K, Curnew RS. Muscle force and activation under stable and unstable conditions. J Strength Cond Res. 2002;16:416-422.

24. Marshall PW, Murphy BA. Core stability exercises on and off a Swiss ball. Arch Phys Med Rehabil. 2005;86:242-249.

25. Marshall P, Murphy B. Changes in muscle activity and perceived exertion during exercises performed on a Swiss ball. Appl Physiol Nutr Metab. 2006;31:376-383.

26. Mcardle WD, Katch FI, Katch VL. Exercise physiology: Energy nutrition and Human Performance. 5th ed. Lippincott Williams \& Wilkins; Baltimore. 2001; P:140.

27. Kravitz L Exercise and resting blood pressure. Health Publications. 2001;16:2122.
28. Hainsworth R. Circulatory responses from lung inflation in anesthetized dogs. Am J Physiol 1974; 226:247-55.

29. William F Ganong. Cardiovasccular regulatory mechanism. Review of Medical Physiology. $22^{\text {nd }}$ ed. Singapore: The McGraw-Hill Company. 2005. p. 597-610.

30. Kravitz L. Resistance Training: Adaptations and Health Implications. Idea Today Health Publications. 1996;14:38- 46

31. Kemi, OJ, Wisloff U. High-intensity aerobic exercise training improves the heart in health and disease. J Cardiopulm Rehabil Prev. 2010;30:2-11.

How to cite this article: Malavia B, Shah S. Cardiovascular response to core stability exercises on Swiss ball and floor in hypertensive individuals. Int J Health Sci Res. 2022; 12(2): 239-245. DOI: https://doi.org/10.52403/ijhsr. 20220234 